\title{
Article \\ Effect of Oral Health Education Using a Mobile App (OHEMA) on the Oral Health and Swallowing-Related Quality of Life in Community-Based Integrated Care of the Elderly: A Randomized Clinical Trial
}

\author{
Ji-Yun Ki ${ }^{1}$, Se-Rim Jo ${ }^{1}$, Kyung-Sook Cho ${ }^{1}$, Jung-Eun Park ${ }^{2}{ }^{\mathbb{D}}$, Ja-Won Cho ${ }^{3}$ and Jong-Hwa Jang ${ }^{1,2, *(1)}$ \\ 1 Department of Public Health, Graduate School, Dankook University, Cheonan-si 31116, Korea; \\ dhkjy2296@gmail.com (J.-Y.K.); serim0222@naver.com (S.-R.J.); cucukxx@hanmail.net (K.-S.C.) \\ 2 Department of Dental Hygiene, College of Health Science, Dankook University, Cheonan-si 31116, Korea; \\ jepark@dankook.ac.kr \\ 3 Department of Preventive Dentistry, College of Dentistry, Dankook University, Cheonan-si 31116, Korea; \\ priscus@dankook.ac.kr \\ * Correspondence: jhj@dankook.ac.kr; Tel.: +82-41-550-1495 or +82-10-4316-6003
}

Citation: Ki, J.-Y.; Jo, S.-R.; Cho, K.-S.; Park, J.-E.; Cho, J.-W.; Jang, J.-H. Effect of Oral Health Education Using a Mobile App (OHEMA) on the Oral Health and Swallowing-Related Quality of Life in Community-Based Integrated Care of the Elderly: A Randomized Clinical Trial. Int. J. Environ. Res. Public Health 2021, 18, 11679. https://doi.org/10.3390/ ijerph182111679

Academic Editor: Paul B. Tchounwou

Received: 7 October 2021

Accepted: 4 November 2021

Published: 7 November 2021

Publisher's Note: MDPI stays neutral with regard to jurisdictional claims in published maps and institutional affiliations.

Copyright: (c) 2021 by the authors. Licensee MDPI, Basel, Switzerland. This article is an open access article distributed under the terms and conditions of the Creative Commons Attribution (CC BY) license (https:// creativecommons.org/licenses/by/ $4.0 /)$.

\begin{abstract}
This study investigated the effect of oral health education using a mobile app (OHEMA) on the oral health and swallowing-related quality of life (SWAL-QoL) of the elderly population in a community-based integrated care project (CICP). Forty elderly individuals in the CICP were randomized into intervention and control groups. OHEMA provided information on customized oral health care management, oral exercises, and intraoral and extraoral massage methods for $50 \mathrm{~min} / \mathrm{session}$, once a week, for 6 weeks. Pre- and post-intervention surveys assessed the unstimulated salivary flow rate, subjective oral dryness, tongue pressure, and SWAL-QoL, which were analyzed using ANCOVA and repeated measures ANOVA. In the intervention group, tongue pressure increased significantly from pre- (17.75) to post-intervention (27.24) $(p<0.001)$, and subjective oral dryness decreased from pre- (30.75) to post-intervention (18.50). The unstimulated salivary flow rate had a higher mean score in the intervention group (7.19) than in the control group (5.04) $(p<0.001)$. The SWAL-QoL significantly improved from pre- (152.10) to post-intervention (171.50) in the intervention group $(p<0.001)$ but did not change significantly in the control group $(p>0.05)$. OHEMA appears to be a useful tool for oral health education for the elderly as it improved the SWAL-QoL, with increased tongue pressure and reduced oral dryness.
\end{abstract}

Keywords: elderly; oral care; oral education; home care; xerostomia; swallowing-related quality of life

\section{Introduction}

South Korea is predicted to become a super-aged society by 2025 [1], and the national health care cost burden is rapidly increasing, particularly in relation to health issues associated with the elderly population. This has highlighted the care of the elderly as a political issue, and a national-level community-based integrated care project (CICP) has been in operation since 2019 [2]. The CICP is a social service system that provides public health care and services that meet the needs of individual residents of the community who require care, to enable them to achieve personal desires and perform activities as cooperating members of the community [2]. The scope of the CICP includes anyone that requires care in South Korea, but the largest proportion of care is directed to elderly people who have been discharged from a hospital, most of whom are reported to have a systemic disease and a low level of oral health [3].

The reported criteria of oral frailty include oral dryness (xerostomia); motor dysfunction of the tongue, mouth, and lips; low tongue pressure; and reduced swallowing 
function [4]. Notably, among oral functions, the decrease in tongue pressure could lead to swallowing dysfunction [5]. More than half of the community-resident elderly are in the high-risk dysphagia group, with an increased risk of problems related to food ingestion, such as anorexia, which can cause nutritional imbalances and have a negative impact on systemic health [6]. Oral health care management is essential for enhancing basic health and quality of life in senescence $[7,8]$. It has been reported that oral dryness, mouth muscle function, and swallowing are positively influenced by continuous oral health care and education [9].

The South Korean government has gradually extended the CICP as a national public health policy [2]. As a result, the demand for the visiting oral care program of the CICP has increased amongst the elderly [10]. However, currently, there are only a few oral health care programs available, while a certain number of existing programs are available to the elderly at care hospitals [11-15]. A recent study showed that oral massage and oral exercises performed on the elderly in care hospitals increased the salivary flow rate, thereby reducing oral dryness and enhancing the swallowing-related quality of life (SWALQoL) $[13,14]$. In addition, oral exercise with gum was reported to improve oral function, including chewing ability, saliva flow rate, and swallowing [16], while mouth gymnastics was shown to improve the swallowing function in the elderly [17].

Most oral health educational material used in earlier studies included posters, PowerPoint presentations, and demonstrations [13,14,18]. The recent coronavirus disease 2019 (COVID-19) pandemic has led to the extended application of video education materials because of the establishment of a non-face-to-face culture [19]. Notably, mobile-based video education programs were found to have positive effects in improving participants ${ }^{\prime}$ knowledge, education-related satisfaction, and practice of the educational content [20-22]. The reports also stated that approximately $50 \%$ of the educational content was received by the participants, compared with that from the other educational materials [23], and an especially strong effect on the education of individual elderly persons was observed as the programs could be watched repeatedly without time or space constraints $[19,24]$. The oral health education using a mobile app (OHEMA) program for the CICP visiting care of the elderly is developed in this study, and future interventions that apply the OHEMA program are anticipated to improve oral health self-care and the practice of oral functional training activities, thus contributing to enhanced oral health [3]

Thus, the purpose of this study was to investigate the effects of the OHEMA program on the unstimulated salivary flow rate (USFR), subjective oral dryness, tongue pressure, and SWAL-QoL in the elderly in the CICP by measuring their health and oral health status.

\section{Materials and Methods}

\subsection{Study Design and Participants}

This study was conducted as a randomized clinical trial. The number of elderly people aged $\geq 65$ years, living in Cheonan-si, Chungcheongnam-do, South Korea, was approximately 73,517, of whom 767 were enrolled in the CICP program. Of the 767 participants, 100 were included for visiting oral health care. The selection criteria were patients with systemic disease or the elderly who sought professional oral health care whether they experienced oral discomfort or not. Among them, 46 participants in the OHEMA program were selected [25]. The inclusion criteria were understanding of the content and purpose of the study; voluntary agreement to participate; ability to communicate without linguistic, auditory, or visual impairment; and normal cognitive ability. The exclusion criteria were missing two or more sessions of the program; a rate of practice of oral health behaviors less than $80 \%$; and a history of systemic disease that could influence oral health, such as administration of a drug affecting saliva secretion, Sjögren syndrome, oral cancer, and stroke. The selected subjects were randomized between the intervention and control groups. The sample size was estimated as 38 using the $G^{*}$ Power program, based on the following conditions: two measurements through repeated measures ANOVA, effect size of 0.25 , significance level of 0.05 , and testing power of 0.85 [26]. Considering a $20 \%$ drop-out rate, 
46 participants (intervention group $n=24$, control group $n=22$ ) were recruited. The final analysis involved 40 individuals (intervention group $n=20$, control group $n=20$ ) who participated in both the pre- and post-intervention surveys (Figure 1).

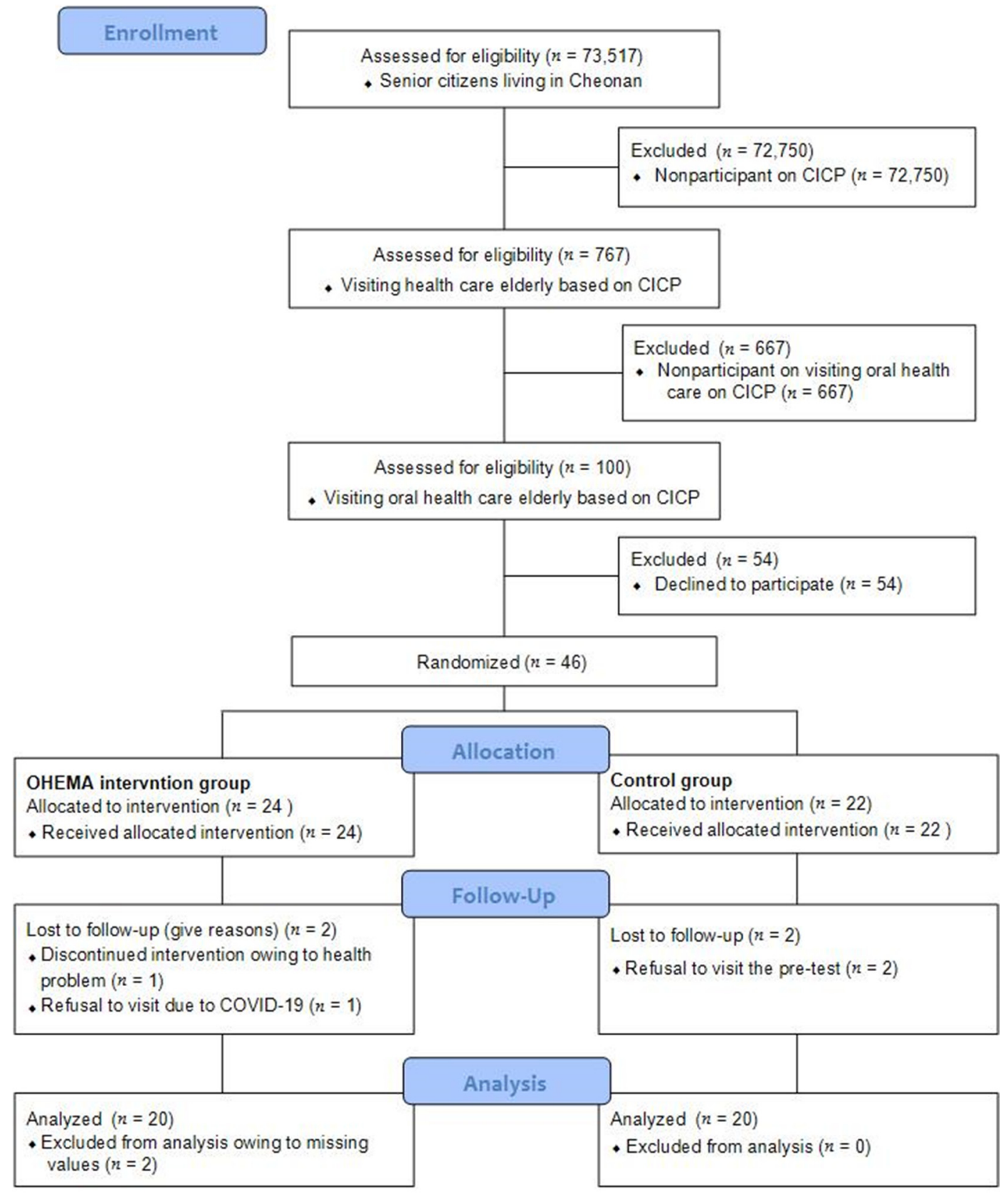

Figure 1. Consolidated standards of reporting trials (CONSORT) diagram of participants.

This study complied with the guidelines of the Helsinki Declaration for the ethical treatment of participants and was conducted with the approval of the Institutional Review Board of the D University (IRB: DKU 2020-05-014-001). Informed consent was obtained from all the participants involved in this study.

The study data were registered in the Clinical Research Information Service (CRIS) as part of the World Health Organization (WHO) International Clinical Trials Registry Platform (trial registration number: KCT0005990). 


\subsection{Intervention}

\subsubsection{OHEMA}

In the OHEMA intervention, a video playing a trot song $(3 \mathrm{~min})$ for oral health education was provided in the introduction to motivate the CICP elderly participants regarding the importance of oral health. The main educational content was shown through four videos consisting of oral exercise with gum and a clock ticking sound ( $7 \mathrm{~min})$, intraoral and extraoral massage (6 min), and a customized oral hygiene intervention including brushing and denture care methods $(15 \mathrm{~min})$. In addition, a workbook and a poster with identical content were provided to the homes [27] (Figure 2). Oral health education media used for OHEMA are presented in the Supplementary Materials (Figures S1-S5).

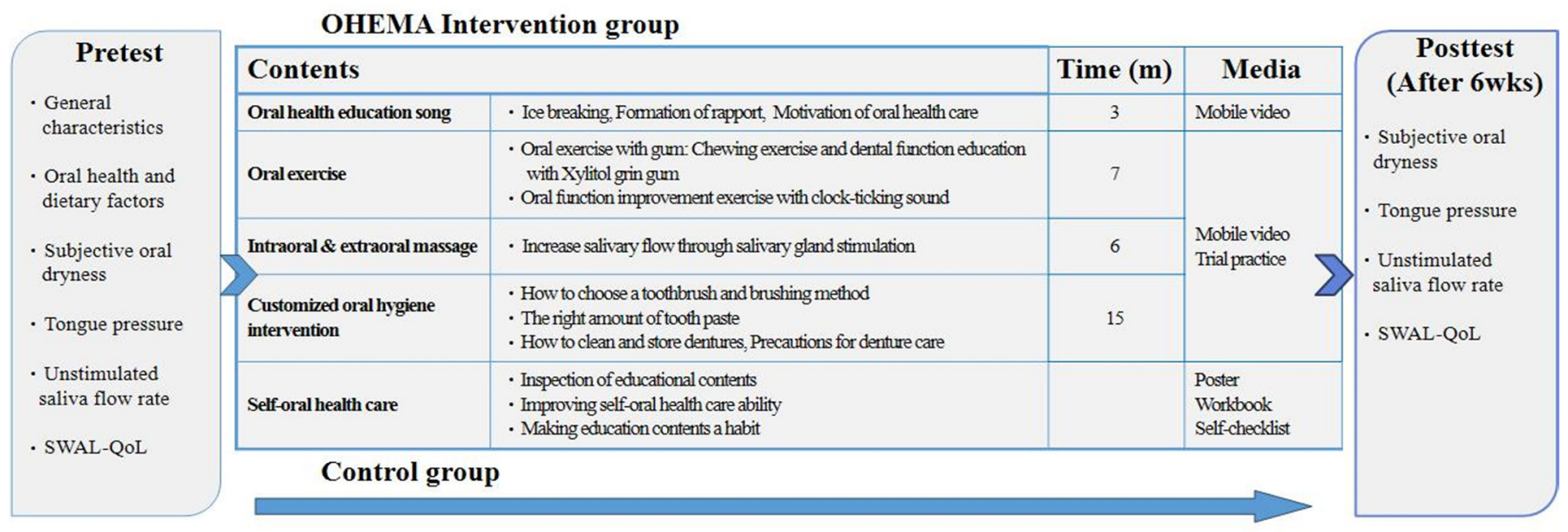

Figure 2. Flowchart of oral health education intervention using mobile app (OHEMA).

\subsubsection{Intervention Group}

The intervention group, after participating in the pre-intervention survey, received the OHEMA intervention for 6 weeks and then participated in the post-intervention survey. The authors helped participants download and trained them on the use of the mobile app before they received OHEMA. The OHEMA program was provided by a member of the research group who visited the home of the participant for customized 1:1 education (50 min per session) based on the participant's characteristics. The intervention group was also guided to practice the oral health education content described in the poster on their own every day and record it on the self-checklist, while the visiting research member checked the level of practice at each visit.

\subsubsection{Control Group}

The control group did not undergo any oral hygiene education or OHEMA intervention. However, the same pre-/post-intervention tests were performed as in the intervention group, and oral health education similar to that in the intervention group was provided after the posttest.

\subsection{Variable Measures}

The OHEMA intervention was performed between 1 February and 30 April 2021, and the data were collected through survey interviews and direct oral examinations. The survey questionnaire was based on a previous study [3] and consisted of general characteristics of the participants (sex, age, smoking, drinking, education, living status, and systemic disease) and oral health behavior (oral examination, oral health education, brushing patterns for a day (yesterday), number of brushings per day, oral care products, and denture use). Oral frailty was assessed based on subjective oral dryness, perceived chewing disability, chewing disability, swallowing difficulty, and inconvenient pronunciation [28,29]; dietary 
factors (meal types, mealtimes, and daily amount of water); activities of daily living (ADL) [30-32] and instrumental activities of daily living (IADL) [33]; mini-mental state examination-Korean version (MMSE-K) [34]; the multidimensional scale of perceived social support (MSPSS) [35,36]; and oral health-related quality of life (OHRQoL) scales (oral health impact profile (OHIP-14), geriatric oral health assessment index (GOHAI), and SWAL-QoL) [37-42]. For oral health status, the number of remaining functional teeth, plaque index (PI) [43], tongue coating index [44], USFR [13], and tongue pressure [45] were measured. For intra- and inter-rater reliability, the authors conducted training before the beginning of the study and confirmed a concordance of $>90 \%$. The results for the intraclass correlation coefficient (ICC) to test the reliability of the dependent variables were as follows: subjective oral dryness $(\mathrm{ICC}=0.82 ; 95 \% \mathrm{CI}=0.65-0.87)$, tongue pressure $(\mathrm{ICC}=0.85 ; 95 \%$ $\mathrm{CI}=0.72-0.92)$, USFR $(\mathrm{ICC}=0.89 ; 95 \% \mathrm{CI}=0.80-0.95)$, and SWAL-QoL $(\mathrm{ICC}=0.75 ; 95 \%$ $\mathrm{CI}=0.53-0.87)$, indicating a high level of reliability.

\subsubsection{Clinical Oral Examination Assessment}

The assessment of oral health status used the WHO [46] criteria, and the number of remaining functional teeth was determined during an oral examination.

The PI was assessed by applying a disclosing solution (Dharma Research, Inc., Miami, FL, USA) to every tooth and evaluating the colored plaque on each tooth surface with a maximum score of 5 and a score of 0 for tooth surfaces without color, with higher scores indicating lower levels of oral health self-care [43]. The tongue coating index was assessed with a score of 1 for the presence and 0 for the absence of tongue coating, with the tongue divided into nine sections of the same width from the tip of the tongue; higher total scores indicated lower levels of oral health care [44]. The USFR was assessed by positioning a Schirmer strip (WF41-1850) cut to the size of $1 \times 17 \mathrm{~cm}$ on the dorsal surface of the tongue and measuring the level of wetness of the strip after 1 min of lightly closing the mouth [13]. Tongue pressure was assessed as the maximum pressure on the JMS tongue pressure device (JMS Co., Ltd., Hiroshima, Japan) in relation to the mean tongue pressure of $30.0 \mathrm{kPa}$ for individuals aged $\geq 65$ years, with a tongue pressure of $20 \mathrm{kPa}$ or below indicating a significantly high risk of diaphragmatic spasm or aspiration pneumonia [45].

\subsubsection{Physical and Cognitive Ability Assessment}

To measure the level of daily activity of the participants, the ADL [30-32] with six categories and the IADL [33] with eight categories were used. The scores ranged between 1 and 3 based on the level of performance, with higher scores indicating lower levels of independent daily activity. In this study, the reliability of ADL was Cronbach's $a=0.76$ and that of IADL was Cronbach's $a=0.87$.

To measure the level of cognitive ability, the MMSE-K was used [34]. The MMSE-K comprises six domains and nine categories to suit the elderly in South Korea, assessing orientation to time and place, memory registration, attention and calculation, memory recall, linguistic function, comprehension, and determination. The maximum score is 30 , and higher scores indicate stronger cognitive abilities. Reliability in this analysis was Cronbach's $a=0.77$.

The MSPSS measures family support, friend support, and special support on a 5-point Likert scale $(1=$ strongly disagree $/ 5=$ strongly agree), with a maximum score of 60 and higher scores indicating higher levels of social support [35,36]. In this analysis, reliability was Cronbach's $a=0.74$.

\subsubsection{Subjective Oral Health Assessment}

The categories of perceived chewing disability, chewing disability, swallowing difficulty, and inconvenient pronunciation, which are used to indicate the level of oral frailty in the National Oral Health Nutrition Investigation, were measured on a 5-point Likert scale ( 1 = strongly disagree $/ 5$ = strongly agree), where mean values were obtained, and higher scores indicated higher levels of oral frailty [28]. For subjective oral dryness, the scale of 
six categories developed by Lee et al. [29] based on a visual analogue scale ( $1=$ strongly disagree $/ 10=$ strongly agree) was used, where the maximum score was 60 and higher scores indicated higher levels of oral dryness. In this study, reliability was Cronbach's $a=0.80$.

\subsubsection{Quality of Life Assessment}

The OHIP-14 [37] consists of 14 categories based on a 5-point Likert scale ( 1 = strongly disagree $/ 5=$ strongly agree) to measure the OHRQoL; the maximum score is 70 and higher scores indicate a higher OHRQoL. Reliability in this analysis was Cronbach's $a=0.91$.

The GOHAI consists of 12 categories based on a 5-point Likert scale $(1=$ strongly disagree $/ 5$ = strongly agree) to measure the quality of life related to oral health; the maximum score is 60 and higher scores indicate a higher OHRQoL [38-40]. Reliability in this analysis was Cronbach's $a=0.81$.

SWAL-QoL consists of 44 categories based on a 5-point Likert scale $(1=$ strongly disagree $/ 5=$ strongly agree) to measure the quality of life related to swallowing; the maximum score is 220 and higher scores indicate a higher QoL [41,42]. Reliability in this analysis was Cronbach's $a=0.95$.

\subsection{Statistical Analysis}

Data were analyzed using the SPSS program (IBM SPSS Statistics 23.0 for Windows, SPSS Inc., Chicago, IL, USA). The normality of the analyzed variables was tested using the Shapiro-Wilk test. The homogeneity of the intervention and control groups was tested using the independent $t$-test, the chi-square test, and Fisher's exact test. To compare the main variables pre- and post-intervention, the paired $t$-test was used, while the effect size was analyzed using ANCOVA and two-way repeated measure ANOVA. The significance level was set to $\alpha=0.05$.

\section{Results}

\subsection{Homogeneity Test}

3.1.1. Homogeneity of the General Characteristics, and Physical and Cognitive Functions

Table 1 presents the results of the homogeneity assessment of the general characteristics of participants. Between the intervention and control groups, homogeneity was verified with respect to sex, age, smoking and drinking, education, living status, systemic disease, and ADL, IADL, MMSE-K, and MSPSS scores ( $p>0.05)$. Notably, an important consideration for OHEMA for the elderly is the level of daily activity or reduction in cognitive ability. The ADL and IADL scores of the participants showed a mild level of disability in both the intervention (1.71 and 12.14, respectively) and control ( 0 and 10.67 , respectively) groups, but the level did not pose a constraint to participation in oral health education or oral health care performance. In addition, both the intervention and control groups showed normal scores $(\geq 24)$ in the MMSE-K in cognitive functional assessment with known cut-off and diagnostic validity.

Table 1. Homogeneity of general characteristics of participants.

\begin{tabular}{ccccc}
\hline Characteristics & Categories & Intervention $(\boldsymbol{n}=\mathbf{2 0})$ & Control $(\boldsymbol{n}=\mathbf{2 0})$ & $\boldsymbol{p}$-Value * \\
\hline \multirow{2}{*}{ Sex } & Male & $10(50.0)$ & $7(35.0)$ & 0.523 \\
& Female & $10(50.0)$ & $13(65.0)$ & \\
\hline \multirow{2}{*}{ Age } & $65-74$ & $7(35.0)$ & $6(30.0)$ & 0.080 \\
& $\geq 75$ & $13(65.0)$ & $14(70.0)$ & \\
\hline \multirow{2}{*}{ Smoking } & Yes & $2(10.0)$ & $3(15.0)$ & 1.000 \\
& No & $18(90.0)$ & $17(85.0)$ & \\
\hline \multirow{2}{*}{ Drinking } & Yes & $3(15.0)$ & $4(20.0)$ & 1.000 \\
& No & $17(85.0)$ & $16(80.0)$ & \\
\hline
\end{tabular}


Table 1. Cont.

\begin{tabular}{ccccc}
\hline Characteristics & Categories & Intervention $(\boldsymbol{n = 2 0 )}$ & Control $(\boldsymbol{n}=\mathbf{2 0})$ & $\boldsymbol{p}$-Value \\
\hline \multirow{2}{*}{ Education } & None & $2(10.0)$ & $4(20.0)$ & 0.588 \\
(years) & 6 & $11(55.0)$ & $8(40.0)$ & \\
\hline \multirow{2}{*}{ Living alone } & $\geq 7$ & $7(35.0)$ & $8(40.0)$ & 0.285 \\
& Yes & $11(55.0)$ & $10(50.0)$ & \\
\hline \multirow{2}{*}{ Systemic disease } & No & $9(45.0)$ & $10(50.0)$ & 1.000 \\
\hline ADL & Yes & $2(10.0)$ & $2(10.0)$ & \\
\hline IADL & & $18(90.0)$ & $18(90.0)$ & 0.614 \\
\hline MMSE-K & & $1.47 \pm 2.37$ & $1.94 \pm 3.02$ & 0.137 \\
\hline MSPSS & & $24.92 \pm 1.83$ & $24.08 \pm 2.31$ & 0.339 \\
\hline
\end{tabular}

Data are presented as $n(\%)$ or mean \pm standard deviation; * chi-square test and Fisher's exact test or independent $t$-test at $\alpha=0.05 ; \mathrm{ADL}=$ activities of daily living; IADL $=$ instrumental activities of daily living; MMSE-K = minimental state examination-Korean version; MSPSS = multidimensional scale of perceived social support.

\subsubsection{Homogeneity of Oral Health and Dietary Factors}

PI, swallowing difficulty, and mealtime in the intervention group were significantly higher than in the control group (Table 2). Regarding the oral health behavior between the two groups, homogeneity was verified for oral examination, oral health education, brushing for a day (yesterday), number of brushings per day, and oral care products $(p>0.05)$. In terms of oral health status, between-group homogeneity was verified for the number of functional teeth, tongue coating index, perceived chewing disability, chewing disability, and inconvenient pronunciation, as well as OHIP-14 and GOHAI ( $p>0.05)$. Among the dietary factors, homogeneity was verified for the meal type and amount of water per day $(p>0.05)$.

Table 2. Homogeneity of oral health and dietary factors between the intervention and control groups.

\begin{tabular}{|c|c|c|c|c|c|}
\hline Factors & Characteristics & Categories & Intervention $(n=20)$ & Control $(n=20)$ & $p$-Value * \\
\hline \multirow{12}{*}{$\begin{array}{l}\text { Oral health } \\
\text { behavior }\end{array}$} & \multirow{2}{*}{ Oral examination } & Yes & $7(35.0)$ & $5(25.0)$ & 0.731 \\
\hline & & No & $13(65.0)$ & $15(75.0)$ & \\
\hline & \multirow{2}{*}{ Oral health education } & Yes & $14(70.0)$ & $13(65.0)$ & 1.000 \\
\hline & & No & $6(30.0)$ & $7(35.0)$ & \\
\hline & \multirow{2}{*}{ Brushing for a day yesterday } & Yes & $20(100.0)$ & $19(95.0)$ & 1.000 \\
\hline & & No & $0(0)$ & $1(5.0)$ & \\
\hline & \multirow{2}{*}{ Number of brushing/d } & $<3$ & $7(35.0)$ & $14(70.0)$ & 0.056 \\
\hline & & $\geq 3$ & $13(65.0)$ & $6(30.0)$ & \\
\hline & \multirow{2}{*}{ Oral care products } & Use & $3(15.0)$ & $6(30.0)$ & 0.451 \\
\hline & & Unuse & $17(85.0)$ & $14(70.0)$ & \\
\hline & \multirow{2}{*}{ Denture use } & Yes & $9(45.0)$ & $11(55.0)$ & 0.752 \\
\hline & & No & $11(55.0)$ & $9(45.0)$ & \\
\hline \multirow{3}{*}{ Oral health status } & Number of functional teeth & & $19.50 \pm 10.14$ & $14.90 \pm 10.87$ & 0.174 \\
\hline & Plaque index & & $2.51 \pm 0.86$ & $1.78 \pm 1.18$ & 0.049 \\
\hline & Tongue coating index & & $3.70 \pm 2.15$ & $3.35 \pm 2.52$ & 0.639 \\
\hline \multirow{4}{*}{ Oral frailty } & Perceived chewing disability & & $3.40 \pm 1.27$ & $3.75 \pm 1.16$ & 0.370 \\
\hline & Chewing disability & & $2.60 \pm 1.31$ & $2.40 \pm 1.19$ & 0.616 \\
\hline & Difficulty of swallowing & & $3.20 \pm 1.06$ & $2.10 \pm 1.21$ & 0.004 \\
\hline & Inconvenient pronunciation & & $3.00 \pm 1.17$ & $2.95 \pm 1.23$ & 0.896 \\
\hline \multirow{2}{*}{$\begin{array}{l}\text { Oral health-related } \\
\text { quality of life }\end{array}$} & OHIP-14 & & $48.75 \pm 12.80$ & $52.80 \pm 12.00$ & 0.308 \\
\hline & GOHAI & & $37.15 \pm 10.31$ & $39.20 \pm 8.92$ & 0.505 \\
\hline
\end{tabular}


Table 2. Cont.

\begin{tabular}{cccccc}
\hline Factors & Characteristics & Categories & Intervention $(\boldsymbol{n}=\mathbf{2 0})$ & Control $(\boldsymbol{n}=\mathbf{2 0})$ & $\boldsymbol{p}$-Value * \\
\hline & Meal type & PR, PS & $16(80.0)$ & $16(80.0)$ & $2(10.0)$ \\
Dietary factors & PR, MS & $2(10.0)$ & $2(10.0)$ & 1.000 \\
& Pealtime (min) & & $2(10.0)$ & $16.55 \pm 8.02$ & 0.042 \\
& Amount of water (cup)/d & $5.75 \pm 2.73$ & $5.55 \pm 3.46$ & 0.840 \\
\hline
\end{tabular}

Data are presented as $\mathrm{n}(\%)$ or mean \pm standard deviation; ${ }^{*}$ chi-square test and Fisher's exact test or independent $t$-test at $\alpha=0.05$; OHIP-14 = oral health impact profile; GOHAI = geriatric oral health assessment index; PR = plain rice; PS = plain side dish; MS = minced side dish; $\mathrm{P}=$ porridge.

\subsubsection{Homogeneity of Dependent Variables}

Table 3 presents the results of the homogeneity of the dependent variables of participants. Between-group homogeneity was verified for subjective oral dryness, tongue pressure, and SWAL-QoL $(p>0.05)$, but the USFR was lower in the intervention group (4.02) than in the control group (5.56) $(p=0.003)$.

Table 3. Homogeneity of dependent variables between the intervention and control groups.

\begin{tabular}{ccccc}
\hline Characteristics & Intervention $(\boldsymbol{n = 2 0 )}$ & Control $(\boldsymbol{n = 2 0 )}$ & $\mathbf{t}$ & $\boldsymbol{p}$-Value \\
\hline Subjective oral dryness & $30.75 \pm 14.97$ & $27.15 \pm 13.16$ & 0.809 & 0.424 \\
Tongue pressure $(\mathrm{kPa})$ & $17.75 \pm 8.46$ & $17.78 \pm 7.15$ & -0.014 & 0.989 \\
USFR $(\mathrm{mm})$ & $4.02 \pm 1.55$ & $5.56 \pm 1.48$ & -3.222 & 0.003 \\
SWAL-QoL & $152.10 \pm 6.83$ & $169.30 \pm 6.92$ & 1.837 & 0.074 \\
\hline
\end{tabular}

Data are presented as mean \pm standard deviation; * independent $t$-test at $\alpha=0.05$; USFR $=$ unstimulated salivary flow rate; SWAL-QoL = swallowing-related quality of life scale.

\subsection{Effects of OHEMA on Oral Health and SWAL-QoL}

The results of comparisons of the dependent variables before and after the 6-week OHEMA program are presented in Table 4.

Table 4. Comparison of oral health and swallowing-related quality of life between the intervention and control groups.

\begin{tabular}{ccccc}
\hline Characteristics & Pretest & Posttest & $p$-Value * & $\begin{array}{c}\text { Between-Group } \\
p \text {-Value }\end{array}$ \\
\hline $\begin{array}{c}\text { Subjective oral dryness } \\
\text { Intervention }(n=20)\end{array}$ & $30.75 \pm 3.15$ & $18.50 \pm 2.82$ & $<0.001$ & $<0.001$ \\
$\quad$ Control $(n=20)$ & $27.15 \pm 3.15$ & $29.25 \pm 2.82$ & 0.176 & \\
\hline Tongue pressure $(\mathrm{kPa})$ & & & & \\
Intervention $(n=20)$ & $17.75 \pm 8.46$ & $27.24 \pm 6.62$ & $<0.001$ & $<0.001$ \\
$\quad$ Control $(n=20)$ & $17.78 \pm 1.75$ & $17.90 \pm 1.65$ & 0.858 & \\
\hline USFR $(\mathrm{mm})$ & & & & \\
Intervention $(n=20)$ & $4.02 \pm 1.55$ & $7.19 \pm 0.19$ & $<0.001$ & \\
Control $(n=20)$ & $5.56 \pm 1.48$ & $5.04 \pm 0.19$ & 0.409 & $<0.001$ \\
$\quad$ SWAL-QoL & & & & \\
Intervention $(n=20)$ & $152.10 \pm 6.83$ & $171.50 \pm 6.82$ & 0.002 & \\
Control $(n=20)$ & $169.85 \pm 6.83$ & $163.30 \pm 6.92$ & 0.265 & \\
\hline
\end{tabular}

Data are presented as mean \pm standard error; ${ }^{*}$ paired $t$-test; ** ANCOVA test for USFR and SWAL-QoL and two-way repeated measure ANOVA for all other variables at $\alpha=0.05$; USFR $=$ unstimulated salivary flow rate; SWAL-QoL = swallowing-related quality of life scale.

For subjective oral dryness, the scores significantly decreased from pre- (30.75) to postintervention (18.50) in the intervention group $(p<0.001)$, with a significant between-group interaction in time verifying the effect of OHEMA in reducing subjective oral dryness 
$(p<0.001)$. For tongue pressure, the scores significantly increased from pre- $(17.75)$ to postintervention $(27.24)(p<0.001)$ in the intervention group, with a significant between-group interaction in time $(p<0.001)$.

The USFR displayed significant variation in the homogeneity test. Analyzing the USFR as a covariate prior to intervention showed the significant effect of the intervention when the measurements before and after intervention were compared $(p<0.001)$. The estimated values controlling the preliminary measurements were higher in the intervention group (7.19) than in the control group (5.04) with statistical significance $(p<0.001)$, thus verifying the positive effect of OHEMA. In addition, analysis of the SWAL-QoL as a covariate prior to intervention, based on the between-group heterogeneity in swallowing disability, showed a significant increase in SWAL-QoL from pre- (152.10) to post-intervention (171.50) in the intervention group $(p<0.001)$, with a significant between-group interaction in time, thus verifying the effect of OHEMA in enhancing the SWAL-QoL $(p=0.012)$.

\section{Discussion}

With accelerated population aging, the demand for visiting oral care management has increased, as public health care policies, through the CICP, receive increased attention to overcome the limitations in the care of the elderly in care hospitals [47-49]. The COVID19 pandemic has also led to more robust non-face-to-face video education programs, highlighting the need for video-based oral health education of the elderly that effectively provides educational content and does not have time or space constraints $[19,23,24]$. Thus, this study analyzed the impact of OHEMA application for 6 weeks on the oral health and SWAL-QoL of the selected CICP elderly population, which was randomized between intervention and control groups.

Most variables, including general characteristics, physical and cognitive functioning, and oral health and dietary factors, showed verified homogeneity between the intervention and control groups. The mean age of the participants in this study was 79 years, and although the ADL and IADL did not vary between the two groups, the scores were lower than those in a previous study of the elderly [48], presumably because of the distribution of elderly individuals aged $\geq 75$ years between the intervention $(65 \%)$ and control $(70 \%)$ groups and the fact that in all groups, $90 \%$ of the elderly had a systemic disease. Nevertheless, all participants showed a level of daily activity that did not prevent participation in the program. In particular, the MMSE-K scores were within the normal range, and the level of education was higher than that of elementary school graduation in $90 \%$ and $80 \%$ of the participants in the intervention and control groups, respectively, indicating a suitable level of cognitive ability and education that would allow a positive effect from oral health education $[47,48]$.

Among the oral health behaviors, the level of unmet dental checkups was high in the intervention $(65 \%)$ and control $(75.0 \%)$ groups, which agreed with the $67.2 \%$ of unmet dental care in the CICP visiting care elderly reported previously [3]. The proportion of denture use was $45.0 \%$ in the intervention group and $55.0 \%$ in the control group, which agreed with the percentage of denture users (50\%) in the study by Jang et al. [3]. The mean number of functional teeth was 19.5 in the intervention group and 14.9 in the control group. The mean number of functional teeth in the participants among the CICP visiting care elderly was 14.92, a level higher than that reported by Jang et al. [3], presumably because the level of oral health was slightly higher in the participants that satisfied the inclusion criteria in this study in comparison to the general participants.

As an indicator of oral frailty, the perceived chewing disability was slightly high in both the intervention (3.40) and control (3.75) groups, while the tongue pressure in the preliminary oral examination was very low in both the intervention (17.75) and control (17.78) groups. This coincides with the high risk of diaphragmatic spasm or aspiration pneumonia at a tongue pressure of $20 \mathrm{kPa}$ in the elderly aged $\geq 65$ years [45]. However, the increase in tongue pressure to $27.24 \mathrm{kPa}$ in the intervention group after the 6-week OHEMA was proof of its positive effect, with a predicted effect of enhancing the SWAL- 
QoL. According to a related earlier study, the muscular strength of the anterior tongue improved after oral exercise intervention [50], supporting the results of this study and verifying the positive effect of oral exercise on tongue pressure in the elderly. A decrease in tongue pressure is one of the oral health problems in the elderly and is deeply correlated with reduced swallowing function and nutritional imbalance, with a potential impact on the physical health of the whole body [42,51]. Thus, oral exercise education is essential in maintaining the basic physical health of the elderly.

Meanwhile, the subjective oral dryness in the intervention group after the 6-week OHEMA decreased from pre- (30.75) to post-intervention (18.50), while the USFR increased from 4.02 to 7.19 . These results coincided with the results of earlier studies on oral health care intervention in the elderly [13,52,53]. In addition, Thanga Raj et al. [54] reported that oral exercise could help reduce oral dryness, based on which OHEMA is predicted to increase the SFR to reduce oral dryness and potentially affect food ingestion in the elderly.

Previous studies on quality of life and health behaviors in the community-resident elderly reported a high correlation with all health behaviors of an individual to protect, maintain, and improve his or her health $[55,56]$. In this study, the OHIP-14 and GOHAI scores were at a moderate level pre-intervention, and the SWAL-QoL significantly increased from pre- (152.10) to post-intervention (171.50). However, the scores were lower than those from an earlier study on the quality of life in the healthy elderly (170.73) [57], which is presumed to be due to the markedly lower level of oral health in the CICP elderly, most of whom had a history of hospital admission to treat a systemic disease [3]. The reduced swallowing function is caused by the decrease in chewing ability and weakening of the mouth muscles $[16,17]$. The swallowing function is deeply correlated with social activities and lifestyle, such as dietary habits [41], with a significant impact on the overall quality of life [57]. It is also closely related to mortality [58]. Providing continuous health care interventions, such as OHEMA, to improve the swallowing function is likely to enhance the quality of life in senescence.

In conclusion, the effectiveness of OHEMA in the visiting oral care CICP elderly has been verified in this study, based on which the program may be nationally implemented. In addition, as the first study of a CICP-based intervention in the field of oral health care, this study lends support to the effective use of programs, such as OHEMA, in future visiting oral care projects. In contrast to the conventional elderly oral health education, which is mainly composed of demonstrations $[13,14,18]$, the use of audio-visual materials such as videos and posters, which promote self-learning, and the consequent established selflearning in this study were shown to be effective in reducing oral dryness and enhancing the SWAL-QoL. In addition, the mobile app videos used in the study intervention were made available on YouTube so that the participants could repeat the learning without time or place constraints $[20,22,24]$. OHEMA is thus anticipated to allow self-motivated learning through repeated watching of the videos even when direct visits of the educators are not possible, while notable significance lies in its potential for expanded application to all elderly participants, including those in the CICP.

Nevertheless, there were several limitations in this study. First, the participants were the CICP elderly among the residents of certain communities, so the potential selection bias prevents generalization to all elderly people in the nation. Second, despite the significant results of enhanced oral health and SWAL-QoL in the intervention group after OHEMA, the program was applied for only 6 weeks, and the long-term effects of the program cannot be readily verified. Third, the SWAL-QoL was measured using a questionnaire with subjective responses, and actual, objective measurements were not taken. Fourth, the oral health knowledge, attitude, and behavior adjustment before and after the OHEMA could not be measured.

Therefore, further studies should categorize the elderly participants based on the characteristics of each individual group and develop a customized program accordingly. It is also necessary to develop a program that contains a variety of mobile app-based content for different circumstances the participants might encounter using a multidisciplinary 
approach. In addition, the study design should include a longitudinal study with long-term monitoring, as well as objective, quantitative measurements of the various psychosocial factors and oral health improvement effects. It is essential to conduct multidisciplinary research and development of suitable educational content and methods to improve oral health care knowledge, attitudes, and behavior in the elderly of different residential types. In addition, we suggest that the OHEMA program used in this study be applied to a larger number of participants to further identify changes in oral health behaviors.

\section{Conclusions}

The 6-week application of OHEMA in the CICP elderly was shown to increase tongue pressure, reduce oral dryness, and improve the SWAL-QoL. Thus, OHEMA is predicted to be useful in activities to promote oral health in the elderly of the CICP or at care hospitals. This study was the first to verify the effects of OHEMA in improving the oral health of the $\mathrm{CICP}$ elderly, and the results collectively suggest that the program could be used in visiting oral care services for the elderly in accordance with the national public health care policy, with an extended scope for nationwide implementation from 2026. Nevertheless, follow-up studies and extended studies for verifying the duration of the effects and counteracting the limitations should be conducted.

Supplementary Materials: The following are available online at https:/ / www.mdpi.com/article/ 10.3390/ijerph182111679/s1, Figure S1: Oral health education trot song; Figure S2: Oral exercise; Figure S3: Intraoral and extraoral massage; Figure S4: Customized oral hygiene intervention; Figure S5: Self oral health care.

Author Contributions: Conceptualization, J.-H.J.; methodology, J.-H.J. and J.-Y.K.; software, J.-Y.K.; validation, J.-H.J., J.-E.P., and J.-W.C.; formal analysis, J.-Y.K. and J.-H.J.; investigation, J.-Y.K., S.-R.J., K.-S.C., and J.-E.P.; resources, J.-E.P. and J.-W.C.; data curation, J.-Y.K. and J.-H.J.; writing-original draft preparation, J.-Y.K. and J.-H.J.; writing-review and editing, J.-H.J. and J.-Y.K.; visualization, J.-Y.K. and J.-H.J.; supervision, project administration, and funding acquisition, J.-H.J. All authors have read and agreed to the published version of the manuscript.

Funding: This work was supported by the Ministry of Education of the Republic of Korea and the National Research Foundation of Korea (NRF-2020S1A5A2A01042603).

Institutional Review Board Statement: The study was conducted according to the guidelines of the Declaration of Helsinki and approved by the Institutional Review Board of the D University (IRB: DKU 2020-05-014-001).

Informed Consent Statement: Informed consent was obtained from all subjects involved in the study.

Data Availability Statement: The data presented in this study are available on reasonable request from the corresponding author.

Acknowledgments: We would also like to thank the visiting oral health care team for cooperating with this study.

Conflicts of Interest: The authors declare no conflict of interest.

\section{References}

1. Korean Statistical Information Service. Results of Population Projections. 2019. Available online: http://kosis.kr/statisticsList/ statisticsListIndex.do?menuId=M_01_01\&vwcd=MT_ZTITLE\&p (accessed on 29 July 2021).

2. Community care promotion committee. Community-Friendly Integrated Care System for Older Persons; Ministry of Health and Welfare, Ministry of the Interior and Safety, Ministry of Land, Infrastructure and Transport: Sejong, Korea, 2018.

3. Jang, J.H.; Cho, J.W.; Kim, Y.J.; Ki, J.Y.; Jo, K.S.; Kim, J.R.; Park, J.E.; Kim, D.H. Preliminary study for the development of a visiting oral health care intervention program for the elderly based on community healthcare. J. Korean Acad. Oral Health 2020, 44, 166-172. [CrossRef]

4. Minakuchi, S.; Tsuga, K.; Ikebe, K.; Ueda, T.; Tamura, F.; Nagao, K.; Furuya, J.; Matsuo, K.; Yamamoto, K.; Kanazawa, M.; et al. Oral hypofunction in the older population: Positions paper of the Japanese society of Gerodontology in 2016. Gerodontology 2018, 35, 317-324. [CrossRef] 
5. Kim, J.Y.; Choi, K.H.; Song, Y.J.; Chung, S.J.; Park, K.W.; Song, K.J.; Son, W.C.; Ahn, H.J. Association of tongue pressure with swallowing function and quality of life in Parkinson's disease. J. Korean Dys. Soc. 2020, 10, 92-96.

6. Park, S.J. Dysphagia risk and associated factors among community-dwelling elders. J. Korean Soc. Food Sci. Nutr. 2015, 44, 49-56. [CrossRef]

7. Yang, B.I.; Park, J.A.; Lee, J.Y.; Jin, B.H. A study on the influencing factors of oral health-related behaviors of the elderly in elderly welfare facilities on oral health-related quality of life. J. Korean Acad. Oral Health 2021, 45, 3-9. [CrossRef]

8. Lee, Y.S.; Lee, H.J. Relationship between oral health status and health related quality of life in elderly people living in long-term care facilities. J. Korean Soc. Oral Health Sci. 2020, 8, 66-72. [CrossRef]

9. Kim, S.H. Comparative analysis of orofacial myofunctional in adults and eldery people. J. Korea Acad. Ind. Coop. Soc. 2019, 20, 303-310.

10. Kim, H.N.; Kim, G.Y.; Noh, H.J.; Kim, N.H. Demand and willing to pay for oral hygiene service in long-term care insurance of elderly. J. Korean Acad. Oral Health 2018, 42, 204-209. [CrossRef]

11. Lee, K.Y.; Lim, S.Y. Effect of professional oral healthcare program on the oral status of elderly residents in long-term care facilities J. Dent. Hyg. Sci. 2016, 16, 432-441. [CrossRef]

12. Jang, J.Y.; Lee, D.H. Effects of oral health promotion program on oral function in the elderly. Korean J. Health Ser. Manag. 2016, 10, 141-151. [CrossRef]

13. Kim, J.H.; Kim, H.Y. Effects of an oral self-care program on the elderly's xerostomia and oral health-related quality of life. $J$. Korean Acad. Community Health Nurs. 2018, 29, 382-392. [CrossRef]

14. Lee, G.R.; Kim, D.R.; Lim, H.N.; Kang, K.H. The effects of the oral care program for improving swallowing function of the elderly using welfare centers on depression, self efficacy, subjective oral health status and swallowing related quality of life. J. Korean Acad. Community Health Nurs. 2020, 31, 166-178. [CrossRef]

15. Lim, C.H.; Lee, H.J.; Park, G.E. Effects of oral care interventions on oral health and oral health-related quality of life among denture-wearing older adults. Korean J. Adult Nurs. 2021, 33, 76-86. [CrossRef]

16. Kim, H.J.; Lee, J.Y.; Lee, E.S.; Jung, H.J.; Ahn, H.J.; Jung, H.I.; Kim, B.I. Simple oral exercise with chewing gum for improving oral function in older adults. Aging Clin. Exp. Res. 2021, 33, 1023-1031. [CrossRef]

17. Kim, Y.S.; Shin, K.H.; Park, J.R.; Chung, S.H.; Choi, H.S. The effect of oral function improvement with oral exercise program by elderly people. J. Korean Soc. Dent. Hyg. 2016, 16, 559-566. [CrossRef]

18. Jin, B.H.; Cho, A.H.; Jung, J.Y.; Song, Y.S.; Park, D.Y.; Hwang, Y.S.; Kim, Y.S. The evaluation of the 2005 oral health education materials made in Korea oral health association. J. Korean Dent. Assoc. 2006, 44, 561-573.

19. Lee, S.G.; Park, S.K. The effects of a video strength exercise on grip strength, balance, TUG in the frail elderly women. J. Korean Soc. Phy. Med. 2013, 8, 91-98. [CrossRef]

20. Kim, E.H.; Shin, S.H. The effect of providing information using a mobile internet terminal on anxiety, discomfort and satisfaction with education among patients undergoing a coronary angiogram. J. East-West Nurs. Res. 2018, 24, 119-129.

21. Kim, Y.J.; Kang, H.Y. Effects of early exercise education using video on exercise knowledge and compliance of elderly patients who undergo total knee replacement surgery. J. Korean Acad. Soc. Nurs. Educ. 2016, 22, 316-325. [CrossRef]

22. Wang, H.J.; Kim, I.O. Effects of a mobile web-based pregnancy health care educational program for mothers at an advanced maternal age. J. Korean Acad. Nurs. 2015, 45, 337-346. [CrossRef]

23. Park, Y.I. Health Promotion and Health Education; Soomoonsa: Seoul, Korea, 2006.

24. Jeong, H.C.; Seong, K.M.; Jeon, M.Y. The effect of a hospital life guidance movie for elderly in-patients. J. Korean Acad. Fundam. Nurs. 2010, 17, 142-148.

25. Cheonan-si Homepage. 2021. Available online: https://www.cheonan.go.kr/kor.do (accessed on 30 April 2021).

26. Faul, F.; Erdfelder, E.; Lang, A.G.; Buchner, A. G*Power 3: A flexible statistical power analysis program for the social, behavioral, and biomedical sciences. Behav. Res. Methods 2007, 39, 175-191. [CrossRef] [PubMed]

27. Ministry of Health and Welfare, The Korea Oral Health Association. Oral Health Education Materials for Elderly Visits Based on Community Healthcare. Ministry of Health and Welfare, The Korea Oral Health Association, 2020. Available online: https:/ / www.dental.or.kr/dental_data3.php (accessed on 1 February 2021).

28. Korea Centers for Disease Control and Prevention. Korea National Health and Nutrition Examination Survey (KNHANES VII). Available online: http:/ / knhanes.cdc.go.kr (accessed on 20 August 2021).

29. Lee, J.Y.; Lee, Y.O.; Kho, H.S. Reliability of a questionnaire for evaluation of dry mouth symptoms. J. Oral Med. Pain 2005, 30, 383-390.

30. Katz, S.; Ford, A.B.; Moskowitz, R.W.; Jackson, B.A.; Jaffe, M.W. Studies of illness in the aged: The index of ADL-a standardized measure of biological and psychological function. JAMA 1963, 185, 914-919. [CrossRef]

31. Won, C.W.; Yang, K.Y.; Rho, Y.G.; Kim, S.Y.; Lee, E.J.; Yoon, J.L. The development of Korea activities of daily living(K-ADL) and Korean instrumental activities of daily living(K-IADL) scale. J. Korean Geriat. Soc. 2002, 6, 107-120.

32. Ko, M.S. Comparative analysis of factors related to activities of daily living, depression and cognitive function between elderly living alone and elderly living with others. J. Hum. Soc. Sci. 2020, 21, 2173-2188.

33. Lawton, M.P.; Brody, E.M. Assessment of older people: Self-maintaining and instrumental activities of daily living. Gerontologist 1969, 9, 179-186. [CrossRef] 
34. Kim, J.M.; Shin, I.S.; Yoon, J.S.; Lee, H.Y. Comparison of diagnostic validities between MMSE-K and K-MMSE for screening of dementia. J. Korean Neuropsychiatr. Assoc. 2003, 42, 1-23.

35. Zimet, G.D.; Powell, S.S.; Farley, G.K.; Werkman, S.; Berkoff, K.A. Psychometric characteristics of the multidimensional scale of perceived social support. J. Pers. Assess. 1990, 55, 610-617. [CrossRef]

36. Park, H.J.; Nguyen, T.; Park, H.J. Validation of multidimensional scale of perceived social support in middle-aged Korean women with diabetes. Asia Pac. J. Soc. Work Dev. 2012, 22, 202-213. [CrossRef]

37. Slade, G.D.; Spencer, A.J. Development and evaluation of the oral health impact profile. Community Dent. Health 1994, 11, 3-11. [PubMed]

38. Atchison, K.A.; Dolan, T.A. Development of the geriatric oral health assessment index. J. Dent. Educ. 1990, 54, 680-687. [CrossRef]

39. Locker, D.; Matear, D.; Stephens, M.; Lawrence, H.; Payne, B. Comparison of the GOHAI and OHIP-14 as measures of the oral health-related quality of life of the elderly. Community Dent. Oral Epidemiol. 2008, 29, 373-381. [CrossRef]

40. Bae, K.H.; Kim, H.D.; Jung, S.H.; Park, D.Y.; Kim, J.B.; Paik, D.I.; Chung, S.C. Validation of the Korean version of the oral health impact profile among the Korean elderly. Community Dent. Oral Epidemiol. 2007, 35, 73-79. [CrossRef]

41. McHorney, C.A.; Bricker, D.E.; Kramer, A.E.; Rosenbek, J.C.; Robbins, J.; Chignell, K.A.; Clarke, C. The SWAL-QOL outcomes tool for oropharyngeal dysphagia in adults: I. Conceptual foundation and item development. Dysphagia 2000, 15, 115-121. [CrossRef]

42. Kim, J.Y.; Kim, D.Y.; Kim, H.H.; Cho, S.R. A validation study of the Korean version of the swallowing-quality of life scale. Commun. Sci. Dis. 2013, 18, 341-347. [CrossRef]

43. Escribano, M.; Figuero, E.; Martín, C.; Tobías, A.; Serrano, J.; Roldán, S.; Herrera, D. Efficacy of adjunctive anti-plaque chemical agents: A systematic review and network meta-analyses of the Turesky modification of the Quigley and Hein plaque index. J. Clin. Periodontol. 2016, 43, 1059-1073. [CrossRef]

44. Winkel, E.G.; Roldán, S.; Winkelhoff, A.J.V.; Herrera, D.; Sanz, M. Clinical effects of a new mouthrinse containing chlorhexidine, cetylpyridinium chloride and zinc-lactate on oral halitosis. J. Clin. Periodontol. 2003, 30, 300-306. [CrossRef] [PubMed]

45. Egashira, R.; Mizutani, S.; Yamaguchi, M.; Kato, T.; Umezaki, Y.; Oku, S.; Tamai, K.; Obata, T.; Naito, T. Low tongue strength and the number of teeth present are associated with cognitive decline in older Japanese dental outpatients: A cross-sectional study. Int. J. Environ. Res. Public Health 2020, 17, 8700. [CrossRef]

46. Peterson, P.E. Grobal policy for improvement of oral health in the 21st century-implications to oral health research of World Health Assembly 2007, World Health Organization. Community Dent. Oral Epidemiol. 2009, 37, 1-8. [CrossRef]

47. Lee, M.H. Evaluating the effectiveness of the application of culture change model for nursing homes in Korea: Changes in quality of life, person-centered climate, depression and isolation. Korean J. Soc. Welf. Res. 2019, 61, 79-98. [CrossRef]

48. Lee, K.H.; Choi, Y.Y.; Jung, E.S. Oral care status and elderly oral health knowledge of care workers and caregivers with regard to patients with dementia. J. Korean Soc. Dent. Hyg. 2019, 19, 79-91.

49. Jang, K.A.; Kim, G.E.; Heo, S.E. The effect of professional oral care by time point on oral health status of inpatients in a nursing hospital. J. Korean Soc. Oral Health Sci. 2019, 7, 92-97. [CrossRef]

50. Seo, S.Y.; Choi, Y.Y.; Lee, K.H.; Jung, E.S. Improvement in oral function after an oral exercise program including whole-body exercises. J. Korean Soc. Dent. Hyg. 2021, 21, 5-16.

51. Chang, K.V.; Wu, W.T.; Chen, L.R.; Wang, H.I.; Wang, T.G.; Han, D.S. Suboptimal tongue pressure is associated with risk of malnutrition in community-dwelling older individuals. Nutrients 2021, 13, 1821. [CrossRef]

52. Kim, Y.J.; Park, K.M. Effects on salivation, xerostomia and halitosis in elders after oral function improvement exercises. J. Korean Acad. Nurs. 2012, 42, 898-906. [CrossRef]

53. Oh, J.Y.; Park, D.B.; Kim, H.J. The relationship between systemic disease and salivary secretion of the elderly and PH of saliva. Asia Pac. J. Multimed. Serv. Conv. Art Hum. Soc. 2019, 9, 427-436.

54. Raj, B.T.; Sreelekha, B.; Manjula, A. Effectiveness of oral exercise on oral function among the elderly. J. Fam. Med. Prim. Care. 2020, 9, 1896-1903.

55. Kim, S.O.; Bark, Y.J. A study of relationship of health behavior and quality of life in the rural elderly. J. Korean Gerontol. Nurs. 2000, 2, 59-71.

56. Botelho, J.; Machado, V.; Proença, L.; Oliveira, M.J.; Cavacas, M.A.; Amaro, L.; Águas, A.; Mendes, J.J. Perceived xerostomia, stress and periodontal status impact on elderly oral health-related quality of life: Findings from a cross-sectional survey. BMC Oral Health 2020, 20, 199-207. [CrossRef]

57. Kim, S.Y. The impact of SWAL-QOL on overall quality of life in normal elderly people: Focusing on Jeonbuk province. J. Korean Cont. Assoc. 2014, 14, 288-297. [CrossRef]

58. Saito, M.; Shimazaki, Y.; Nonoyama, T.; Tadokoro, Y. Association of oral health factors related to oral function with mortality in older Japanese. Gerodontology 2020, 38, 166-173. [CrossRef] [PubMed] 